\title{
Recent GPS results on the geodynamics of the area around Sofia (Central-Western Bulgaria)
}

\section{Нови GPS резултати за геодинамиката на района около София (Централна-Западна България)}

\author{
Nikolay Dimitrov ${ }^{1}$, Radoslav Nakov ${ }^{2}$ \\ Николай Димитров ${ }^{1}$ Радослав Наков ${ }^{2}$ \\ ${ }^{1}$ National Institute of Geophysics, Geodesy and Geography, Bulgarian Academy of Sciences, Acad. G. Bonchev str. bl. 3 , \\ 1113 Sofia, E-mail: ndimitrov@geophys.bas.bg \\ ${ }^{2}$ Geological Institute, Bulgarian Academy of Sciences, Acad. G. Bonchev str. bl. 24, 1113 Sofia, E-mail: radnac@geology.bas.bg
}

Keywords: geodynamics, GNSS, recent crustal movements.

\section{Introduction}

The study of contemporary crustal movements is one of the priority areas of Earth sciences. GNSS technology allows the study of modern tectonics because it provides quantitative estimates of modern movements of the Earth's crust. The study of the crustal movements is a complex problem for which the analysis of geodetic data provides important information. The area of interest of this study is bounded to the north of the southern slopes of the Balkan Mountains, to the south to the southern slopes of the Rila Mountains, to the west - the western border of Bulgaria and to the east - the beginning of the Upper Thracian plain. The region is of particular interest due to its high population density and high concentration of industrial facilities and resources. Possible strong earthquakes and related hazardous processes such as landslides, settlements and collapses may cause material damage and have a negative psychological effect on the population. The above shows the social importance of the study area and the need to obtain reliable geological and geodetic data for its current geodynamic activity.

\section{Geodynamic setting}

The present-day geodynamics of the area as well as the entire territory of South-Western Bulgaria is defined by the neotectonic extensional processes in the South Bulgarian Extensional Region (Burchfiel et al., 2000), part of the broad East MediterraneanBalkan Extensional system. Presently, based on geological data the extension is in a general N-S direc- tion which results in tectonic structures with general trend NW-SE to E-W. These structures are clearly expressed morphologically and define the topography of the area - elevated mountains (horsts) and subsided lands (grabens). In the area of Sofia historically are known few several stronger earthquakes with suggested magnitudes 5.5-7.0 (Yosifov et al., 2018). The last one, of magnitude $\mathrm{Mw} 5.6$ occurred on May 22, 2012 to the NW of Sofia around Pernik town (Radulov et al., 2012) along a fault of NW-SE trend.

Previously obtained results from GPS measurements show velocities from $1-2 \mathrm{~mm}$ to $5-6 \mathrm{~mm}$ (Kotzev et al., 2001a, b, 2006) pointed in general to the S-SE and moving in the same direction in respect to Eurasia. Combined historical geodetic data from leveling and GPS data (Kotzev et al., 2006; Dimitrov, Georgiev, 2011; Dimitrov, 2019) have demonstrated the feasibility of this methodology for the dynamic study of the area. They provided also estimates of the active strain in the Earth's crust. All studies show the presence of modern crustal movements in the area. Combined geological and geodetic data show that at a large scale, the area exhibits the behavior of a more or less homogeneous geodynamic unit, moving and extending to the S-SE. Extension is combined with strike-slip displacement in generally NW-SE direction and rotation. Local zones of extension or compression are expressed due to velocity differences between tectonic blocks with approximately one and the same direction of motion (Kotzev et al., 2001b). However, local inhomogeneous localities were clearly found, that need 
to be further investigated in aim to obtain more accurate and reliable GPS data on the geodynamics of the area and the related geological hazards.

\section{GPS network for geodynamic studies in the area of Central-Western Bulgaria}

To study the modern movements of the Earth's crust during the period 1996-1997, a geodynamic network was built in the area around Sofia, covering Central-Western Bulgaria. The network is designed for high-precision GNSS measurements, determination of coordinates and velocities of points, calculation of active strain in the area and long-term monitoring crustal movements. The first GNSS measurements of the Sofia Geodynamic Network were made in 1997. Full measurement of the entire network with processing and analysis of the results has so far been performed only in two epochs 1997 and 2000 (Kotzev et al., 2001a, 2006).

During the period 2001-2019, the network was condensed and expanded with the stabilization of new points (Georgiev et al., 2002). GPS campaigns were periodically conducted for partial measurements of the network to estimate the crustal movements in the area.

\section{GNSS measurements 2020, processing and preliminary results}

At the end of 2019th, the project "Monitoring of geodynamic processes in the region of Sofia" of the Department of Geodesy, the National Institute of Geophysics, Geodesy and Geography at BAS, funded by the National Research Fund, was launched. This allowed for a new comprehensive measurement of

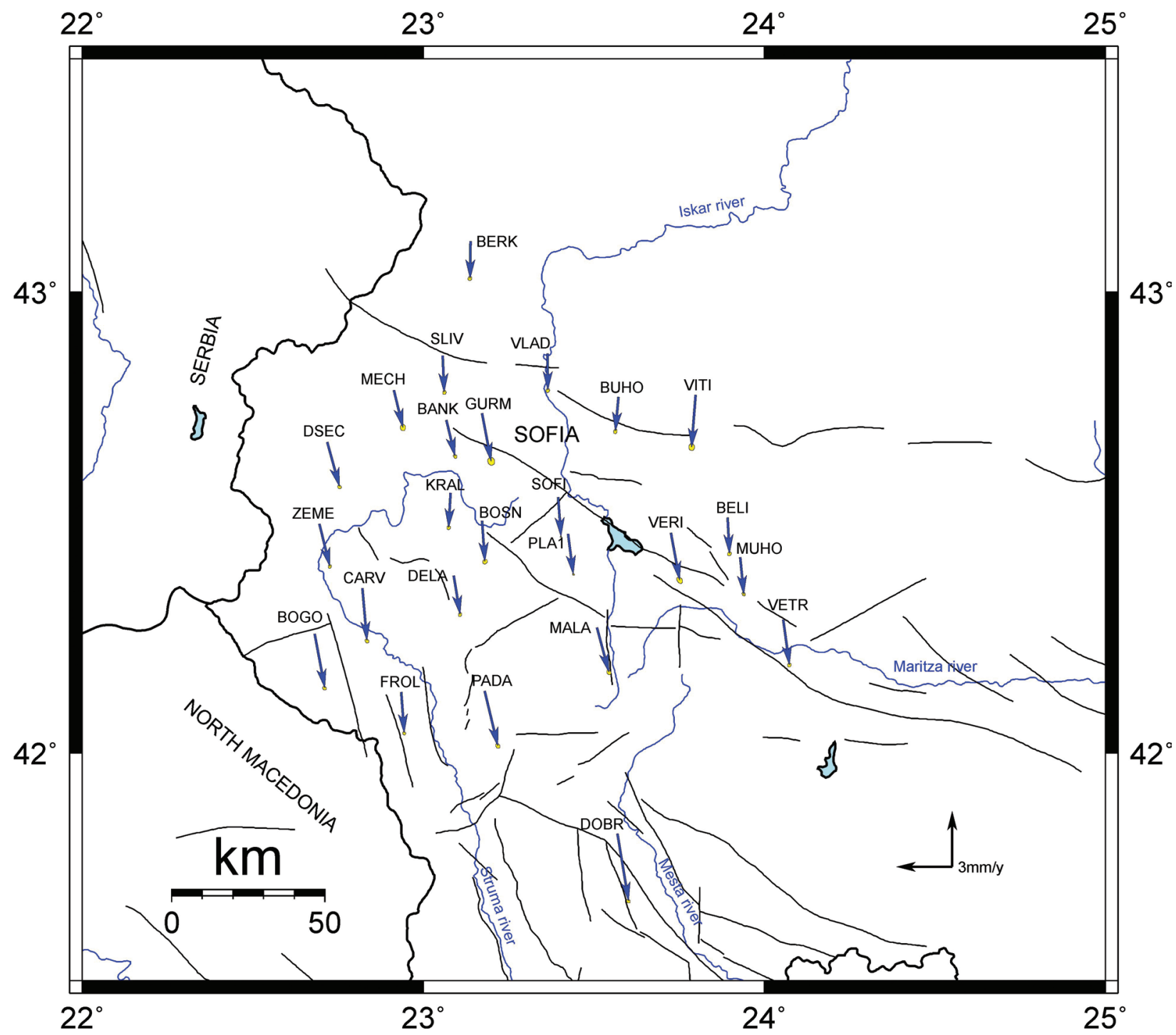

Fig. 1. Horizontal velocities relative to Eurasia with main faults, shown as black lines 
the geodynamic network. The campaign was accomplished in the summer of 2020th and the data were recently processed. The measurements were performed with the Bernese GNSS software v5.2 software developed at the Astronomical Institute in Bern, Switzerland (Dach et al., 2015). Estimation includes data from campaigns 1997 (Reilinger et al., 1997), 2000 (Burchfiel, 2000) and 2020 years. All obtained velocities are relative to Eurasia (Fig. 1).

The obtained result clearly provides new more accurate GPS geodynamic data on the considered area. All obtained velocities are extremely reliable because theirs $3 \sigma$ errors are very small. All velocities clearly exceed $1.5-2 \mathrm{~mm} / \mathrm{y}$ reaching up to $3-4 \mathrm{~mm} / \mathrm{y}$. As a general tendency the velocities tend to increase from North to South. In the northernmost area (NNW of Sofia) dominate velocities of about $1.5 \mathrm{~mm}$ (stations BERK, VLAD, BUHO, SLIV). In the area southern of Sofia dominate velocities of $2-3 \mathrm{~mm} / \mathrm{y}$ (stations DSEC, CARV, BOGO, VERI, PADA, VETR, MALA). Further southern the velocity of DOBR is almost $4 \mathrm{~mm} / \mathrm{y}$, which is the highest in the area. This pattern suggests also increasing rate of extension to the south. The behavior of some stations with velocities from earlier campaigns (e.g. VLAD, BUHO), that were showing significant deviation now fit in the general trend. This shows that the reason was the lack of accuracy due to the short period, but not to tectonic reasons.

In general the velocities are oblique to the faults. This is better expressed in the northern part (stations SLIV, MECH, BANK, GURM, BOSN, VERI), suggesting oblique extension to the structures. Instead, in the SW part (stations ZEME, CARV, FROL, PADA) the velocities are parallel to some faults, suggesting strike-slip deformation. North of station BOGO extension is probable on the northern located fault (Kustendil fault) and strike-slip deformation to the eastern fault.

\section{Conclusions}

The newly acquired velocities from three campaigns 1997, 2000 and 2020 years confirm that the general tendency of movement of the stations in the region of Central-Western Bulgaria is in the south direction with respect to stable Eurasia. The velocities tend to increase from north to south. This pattern is in agreement with the extensive movement of Southern Bulgaria and Northern Greece. The new results provide much better aquiracy, reliability and local details. They are a reliable base for further geodynamic interpretations.
Acknowledgements: This paper has been made available with the financial support provided by National Science Fund, Bulgaria, call identifier "Competition for financial support of basic research projects - 2019" Project "Monitoring of geodynamic processes in the area of Sofia". Contract No KP06-H 34/1

\section{References}

Burchfiel, B. C. 2000. Bulgaria 2000 - The GAGE Facility operated by UNAVCO. Inc., GPS/GNSS Observations Dataset, https://doi.org/10.7283/T5N877X4.

Burchfiel, B. C., R. Nakov, Tz. Tzankov, L. H. Royden. 2000. Cenozoic extension in Bulgaria and Northern Greece: The northern part of the Aegean extensional regime: - In: Bozkurt, E., J. A. Winchester, J. D. A. Piper (Eds.), Tectonics and Magmatism in Turkey and the Surrounding Area. Geol. Soc., Sp. Publ., 173, 325-352.

Dach, R., S. Lutz, P. Walser, P. Fridez (Eds). 2015. Bernese GNSS Software Version 5.2. User Manual. Astronomical Institute, University of Bern, Bern Open Publishing; DOI: 10.7892/boris.72297; ISBN: 978-3-906813-05-9.

Dimitrov, N. 2019. Deformation analysis in Central-West Bulgaria using triangulation and GPS data. - Reports on Geodesy and Geoinformatics, 108, 23-26; DOI: 10.2478/ rgg-2019-0009.

Dimitrov, N. I. Georgiev, 2011. Crustal strain from GPS and triangulation data in Central-Western Bulgaria. - Rev. Bulg. Geol. Soc., 72, 1-3, 27-32.

Georgiev, I., L. Pashova, D. Dimitrov, G. Nikolov, S. Shanov, E. Botev, S. Gospodinov, I. Zdravchev, B. Alexandrov. 2002. GPS network for geodynamic investigation in the region of Southwest Bulgaria. - In: Book of Abstracts 3rd Balkan Geophysical Congress and Exhibition, 24-28 June, Sofia, 345-346.

Kotzev, V., R. Nakov, B. C. Burchfiel, R. W. King, N. Dimitrov. 2001a. Active deformation in the Sofia region inferred from geodetic measurements. - In: Proceedings of the Final Conference of the International Project "Expert Assessment of Land Subsidence related to Hydrogeological and Engineering Geological Conditions in the Regions of Sofia, Skopje and Tirana", 27-30 June, Sofia, 99-102.

Kotzev, V., R. Nakov, B. C. Burchfiel, R. W. King. 2001 b. GPS constraints on the kinematics of Southwestern Bulgaria. - C. R. Acad. Bulg. Sci., 54, 7, 51-54.

Kotzev, V., R. Nakov, Tz. Georgiev, B. C. Burchfiel, R. W. King. 2006. Crustal motion and strain accumulation in western Bulgaria. - Tectonophys., 413, 3-4, 127-145.

Radulov, A., M. Yaneva, S. Shanov, K. Kostov, V. Nikolov, N. Nikolov. 2012. Coseismic geological effects related to the May 22, 2012 Pernik earthquake, Western Bulgaria. In: Proceedings of the National Conference "Geosciences 2012”, Sofia, Bulg. Geol. Soc., 121-122.

Reilinger, R., L. Royden, R. King, C. Burchfiel. 1997. Bulgaria 1997. The GAGE Facility Operated by UNAVCO. Inc., GPS/GNSS Observations Dataset; https://doi.org/10.7283/ HFEC-PB89.

Yosifov, D., I. Paskaleva, E. Botev, B. Rangelov. 2018. The Seismic Risk for Sofia. Sofia, NTS MDGM, 207 p. (in Bulgarian). 